\title{
Relaxin Induces an Extracellular Matrix-degrading Phenotype in Human Lung Fibroblasts In Vitro and Inhibits Lung Fibrosis in a Murine Model In Vivo
}

\author{
Elaine N. Unemori, ${ }^{\star}$ Lesley B. Pickford, Adam L. Salles, Christopher E. Piercy, Beverly H. Grove, Mark E. Erikson, \\ and Edward P. Amento \\ Connective Therapeutics, Inc., Palo Alto, California 94303
}

\begin{abstract}
Pulmonary fibrosis is the common end stage of a number of pneumopathies. In this study, we examined the ability of the human cytokine, relaxin, to block extracellular matrix deposition by human lung fibroblasts in vitro, and to inhibit lung fibrosis in a bleomycin-induced murine model. In vitro, relaxin (1-100 $\mathrm{ng} / \mathrm{ml}$ ) inhibited the transforming growth factor- $\beta$-mediated over-expression of interstitial collagen types I and III by human lung fibroblasts by up to $45 \%$ in a dose-dependent manner. Relaxin did not affect basal levels of collagen expression in the absence of TGF- $\beta$-induced stimulation. Relaxin also blocked transforming growth factor- $\beta$-induced upregulation of fibronectin by $80 \%$ at the highest relaxin dose tested $(100 \mathrm{ng} / \mathrm{ml})$. The expression of matrix metalloproteinase-1, or procollagenase, was stimulated in a biphasic, dose-dependent manner by relaxin. In vivo, relaxin, at a steady state circulating concentration of $\sim 50 \mathrm{ng} / \mathrm{ml}$, inhibited bleomycin-mediated alveolar thickening compared with the vehicle only control group $(P<$ 0.05). Relaxin also restored bleomycin-induced collagen accumulation, as measured by lung hydroxyproline content, to normal levels $(P<0.05)$. In summary, relaxin induced a matrix degradative phenotype in human lung fibroblasts in vitro and inhibited bleomycin-induced fibrosis in a murine model in vivo. These data indicate that relaxin may be efficacious in the treatment of pathologies characterized by lung fibrosis. (J. Clin. Invest. 1996. 98:2739-2745) Key words: pulmonary fibrosis $\bullet$ relaxin $\bullet$ collagen $\bullet$ collagenase
\end{abstract}

\section{Introduction}

The etiological basis of interstitial lung disease is varied or often unknown. A common outcome of these pulmonary diseases is fibrosis, characterized by an increase in fibroblast number and enhanced collagen deposition. These changes lead to a disruption of normal lung structure, including alveolar thickening and a loss of functional alveolar capillaries, resulting in impaired lung function $(1,2)$.

Address correspondence to Dr. E.N. Unemori, Connective Therapeutics, Inc., 3400 W. Bayshore Rd., Palo Alto, CA, 94303. Phone: 415-843-2800; FAX: 415-843-2899; E-mail: elaine_unemori@connec tive.com

Received for publication 14 August 1996 and accepted in revised form 16 October 1996.

J. Clin. Invest.

(c) The American Society for Clinical Investigation, Inc.

0021-9738/96/12/2739/07 \$2.00

Volume 98, Number 12, December 1996, 2739-2745
The polypeptide cytokine/growth factor, relaxin, is elevated in the serum during pregnancy (3), and is thought to play a role in the structural remodeling of the interpubic ligament and cervix in preparation for parturition. The administration of exogenous relaxin to estrogen-primed animals causes a loosening of or decrease in the density of collagen bundles present in the ligament (4). These observations previously led us to examine the effect of recombinant human relaxin on the connective tissue phenotype of human dermal fibroblasts (5). We found that relaxin decreased the synthesis and secretion of interstitial collagens, increased the expression of the matrix metalloproteinase, procollagenase, and decreased the production of tissue inhibitor of metalloproteinases by these cells. Subsequently, we extended these observations to include assaying relaxin's effect on collagen accumulation in vivo in two rodent models of fibrosis: (1) collagen deposition within a polyvinyl alcohol sponge implanted subcutaneously in rats; and (2) capsule formation around a subcutaneously placed osmotic pump in mice (6). In both in vivo models, relaxin decreased the deposition of collagen, measured as hydroxyproline content of the sponge, and by histological and electron microscopic examination of the capsule.

In the present study, we examined the ability of recombinant human relaxin to alter the connective tissue phenotype of human lung fibroblasts, both in vitro and in vivo. We found that relaxin decreased transforming growth factor- $\beta$-induced overexpression of procollagen types I and III by normal human lung fibroblasts in vitro. Relaxin also increased the synthesis and secretion of procollagenase (matrix metalloproteinase-1) in a dose-dependent manner in these cells. In vivo, relaxin blocked bleomycin-induced pulmonary fibrosis in mice, as assessed both histologically and biochemically. Together, these data indicate that relaxin may provide a means to regulate excessive collagen deposition in disease states characterized by pulmonary fibrosis.

\section{Methods}

Cell culture. Normal human lung fibroblasts obtained from young adult donors were purchased from the American Type Culture Collection (ATCC CCL202, CCL210; Rockville, MD) and passaged according to vendor instructions in MEM supplemented with $10 \%$ fetal bovine serum, nonessential amino acids, and $2 \mathrm{mM} \mathrm{L}$-glutamine. Cells were seeded at a density of $1.25 \times 10^{5} \mathrm{cells} / \mathrm{cm}^{2}$ in the presence of serum but were switched to MEM supplemented with $0.2 \%$ lactalbumin hydrolysate and $2 \mathrm{mM}$ L-glutamine (MEM-LH) for experiments.

Reagents and animals. Recombinant human relaxin (Lot M3RD211 or 9997-96) was manufactured at Genentech, Inc. (South San Francisco, CA) $\left[{ }^{3} \mathrm{H}\right]$ proline $(43 \mathrm{Ci} / \mathrm{mmol})$ was purchased from Amersham (Arlington Heights, IL). Ascorbic acid and $\beta$-aminopropionitrile (BAPN) were purchased from Sigma Chemical Co. (St. Louis, MO) and prepared immediately before use as 50 and $80 \mathrm{mg} / \mathrm{ml} \mathrm{stocks,}$ respectively. Bleomycin (15 U/vial, Blenoxane) (Burns Veterinary 
Supply, Carrollton, TX) was dissolved in $1 \mathrm{ml}$ saline for injection (Baxter, McGaw Park, IL) immediately before use and warmed to $37^{\circ} \mathrm{C}$ before injection. $20 \mathrm{mM}$ sodium acetate, $\mathrm{pH} 5.0$, and $10 \mathrm{mM}$ sodium citrate, pH5.0 (Sigma Chemical Co.), were prepared in sterile water (Baxter). Saline, bleomycin, acetate, and citrate solutions were filtered through a $0.2-\mu \mathrm{m}$ filter before injection. Female CBA/J mice (8-10 wk old) were obtained from Harlan Sprague Dawley (Indianapolis, IN) and housed according to NIH guidelines. Mice weighed between 16-22 $\mathrm{g}$ at the start of the experiments. Mice had ad libitum access to standard rodent lab chow and tap water, with a $12 \mathrm{~h}$ light cycle. Room temperature was maintained between 20 and $23^{\circ} \mathrm{C}$.

Biosynthetic labeling of collagen. Collagen was biosynthetically labeled with $\left[{ }^{3} \mathrm{H}\right]$ proline $(25 \mu \mathrm{Ci} / \mathrm{ml})$ in the presence of ascorbate $(50$ $\mu \mathrm{g} / \mathrm{ml})$ and BAPN (80 $\mu \mathrm{g} / \mathrm{ml})$ in MEM-LH for $24 \mathrm{~h}$ (5). Labeled proteins were electrophoresed on 4-12\% SDS gradient gels (NOVEX, San Diego, CA) after reduction. To identify collagen bands, radiolabeled bands were tested for sensitivity to bacterial collagenase (Advance Biofactures, Inc., Lynbrook, NY) overnight at $37^{\circ} \mathrm{C}$ before reduction. Gels were enhanced (Amplify, Amersham, Inc.), dried, and exposed to x-ray film. Procollagen and fibronectin bands were scanned using a digital imaging system (Alpha Innotech Corp., San Leandro, CA).

Western immunoblotting. Conditioned media were electrophoresed on $4-12 \%$ SDS gradient gels under reducing conditions, as described above, and transferred electrophoretically to nitrocellulose using $25 \mathrm{mM}$ sodium phosphate, $\mathrm{pH} 6.5$, overnight at $100 \mathrm{~mA}$. Blots were stained with a rabbit polyclonal anti-human fibronectin antibody (Promega, Madison, WI), followed by a biotinylated anti-rabbit secondary antibody (Cappel, West Chester, PA). Bromo-4-chloro-3indoyl phosphate and nitroblue tetrazolium substrates were purchased from Boehringer Mannheim (Mannheim, Germany), and used according to manufacturer's instruction.

Detection of matrix metalloproteinases. Zymography of secreted proteins by electrophoresis in $10 \%$ polyacrylamide gels impregnated with gelatin $(1 \mathrm{mg} / \mathrm{ml}$, type I, Sigma Chemical Co.) was used to detect matrix metalloproteinases, as previously described (7). Conditioned media from cultured cells were mixed with Laemmli sample buffer, modified to contain $2.5 \%$ SDS, and electrophoresed at $15 \mathrm{~mA}$. Gels were washed in $2.5 \%$ Triton $\mathrm{X}-100$ for $30 \mathrm{~min}$, and then incubated overnight in substrate buffer $\left(50 \mathrm{mM}\right.$ Tris, $\left.\mathrm{pH} 8.0,5 \mathrm{mM} \mathrm{CaCl}_{2}\right)$. After staining with Coomassie Blue R250, metalloproteinases appeared as light bands on a blue background.

Induction of lung fibrosis with bleomycin. Two independent experiments were performed to test relaxin's ability to modulate pulmonary fibrosis after induction with bleomycin. The design of both experiments was identical, as follows. CBA/J mice were treated either with bleomycin to induce fibrosis or were injected with saline. Within each group of mice, half were treated with relaxin and half with vehicle. This design resulted in four experimental groups: (a) saline-vehicle-treated; $(b)$ saline-relaxin-treated; $(c)$ bleomycin-vehicletreated; $(d)$ bleomycin-relaxin-treated. Bleomycin $(120 \mathrm{U} / \mathrm{kg})$ was administered in $0.2 \mathrm{ml}$ via the lateral tail vein (8) in a single intravenous bolus $(0.2 \mathrm{ml} / \mathrm{min})$; control animals received $0.2 \mathrm{ml}$ saline via the same route. $7 \mathrm{~d}$ later, all mice were briefly anesthetized and subcutaneously implanted with osmotic pumps (model 2002; Alza, Palo Alto, CA), which were preloaded to deliver a sustained relaxin dose of $0.5 \mathrm{mg} / \mathrm{kg}$ per day or an equivalent volume of vehicle for $19 \mathrm{~d}$. In the first experiment, the lot of relaxin (M3RD211) used was formulated with citrate $(10 \mathrm{mM}, \mathrm{pH}$ 5.5), which was therefore used as diluent and the vehicle control. In the second experiment, the lot of relaxin used (9997-96) was formulated in acetate $(20 \mathrm{mM}, \mathrm{pH} 5.0)$; therefore, acetate was used as diluent and vehicle. In both cases, relaxin was diluted to the appropriate concentration $(1 \mathrm{mg} / \mathrm{ml})$ just before loading into the pumps. Mice were monitored daily for general health and weighed daily. $14 \mathrm{~d}$ after pump implantation $(21 \mathrm{~d}$ after bleomycin administration), the animals were killed, blood collected for determination of circulating relaxin concentration, and lungs removed for either histology or biochemical analysis of collagen content.
Histology. Lungs were perfused in situ through the right ventricle with saline, and then inflated and fixed with $10 \%$ buffered formalin. Lungs were ligated at the bronchi, excised, further fixed by immersion in $10 \%$ buffered formalin for at least $24 \mathrm{~h}$ before paraffin embedding, sectioning, and H\&E and Masson's trichrome staining. Alveolar thickness and fibrosis were scored in ten random fields at three levels through each lung, according to the Ashcroft method (9), by a veterinary histopathologist blinded to the treatment groups.

Hydroxyproline assay. According to previous reports, the collagen content of lungs peaks $3 \mathrm{wk}$ after a single administration of bleomycin $(8,10)$. Mice were killed 3 wk after the start of the study, and lungs were removed for collagen quantitation by hydroxyproline measurement. Briefly, whole lungs were freeze-dried, then hydrolyzed with $6 \mathrm{~N}$ hydrochloric acid, $0.1 \%$ phenol for $24 \mathrm{~h}$ at $110^{\circ} \mathrm{C}$. Amino acid content was analyzed on a Beckman Model 6300 amino acid analyzer (Beckman Instruments Inc., Fullerton, CA). Hydroxyproline content was expressed as nMole/lung. Processing of the tissue and amino acid quantitation were done at the Beckman Protein and Nucleic Acid Facility, Stanford University.

Quantitation of serum levels of relaxin by ELISA. Levels of relaxin in serum were measured in a quantitative sandwich immunoassay. Briefly, wells of a 96-well microtiter plate (Maxisorp Immunomodules; Nunc, Inc., Naperville, IL) were coated overnight with affinity purified anti-recombinant human relaxin polyclonal antibody, sera were diluted in phosphate buffered saline containing Tween 20, Thimerosal, bovine serum albumin (Sigma Chemical Co.) and normal goat IgG (Organon Teknika-Cappel, Durham, NC), and $100 \mu \mathrm{l}$ were added to wells in duplicate. After an overnight incubation, wells were washed and $100 \mu \mathrm{l}$ of affinity-purified, peroxidase-conjugated, antirecombinant human relaxin polyclonal antibody were added to each well. After an appropriate incubation period, wells were washed and $100 \mu \mathrm{l}$ of a tetramethylbenzidine solution were added to each well. After color development, the reaction was stopped, absorbances at $450 / 630 \mathrm{~nm}$ were measured, and relaxin concentrations in the sera were determined by entering data into a four-parameter logistic curve-fitting program. The assay has been validated for use with murine serum, shows no detectable cross-reactivity with natural murine relaxin, and has a lower limit of detection of $20 \mathrm{pg} / \mathrm{ml}$.

Statistics. The Student Newman-Keuls $t$ test was used for assessing significance of differences among multiple groups (11)

\section{Results}

Relaxin decreased procollagen and fibronectin overexpression in vitro. In normal lung fibroblasts, basal levels of procollagen expression, as assessed by $\left[{ }^{3} \mathrm{H}\right]$ proline incorporation, were not markedly altered by the addition of relaxin (1-100 ng/ml) (Fig. 1, $A$ and $B)$. When cells were treated with TGF- $\beta$ ( $1 \mathrm{ng} / \mathrm{ml})$, procollagen expression increased fourfold, consistent with findings in many previously described cell types (12). Procollagen bands were identified by sensitivity to digestion with purified bacterial collagenase (data not shown). When relaxin (1-100 $\mathrm{ng} / \mathrm{ml}$ ) was added simultaneously with TGF- $\beta$, procollagen expression was decreased in a dose-dependent manner, by up to $44 \%$ at the highest relaxin dose tested. Fibronectin expression was upregulated 12 -fold by $24 \mathrm{~h}$ of treatment with TGF- $\beta$ (Fig. $1 C$ ). The addition of relaxin decreased fibronectin expression in a dose-dependent manner by $80 \%$ at a relaxin dose of 100 $\mathrm{ng} / \mathrm{ml}$. Fibronectin was identified as a band at $\sim 220 \mathrm{kD}$ by Western immunoblotting (Fig. $1 \mathrm{D}$ ) and by insensitivity to digestion with bacterial collagenase (data not shown).

Relaxin induced expression of procollagenase in vitro. Lung fibroblasts were treated with relaxin at concentrations ranging from $1 \mathrm{pg}-1 \mu \mathrm{g} / \mathrm{ml}$ in MEM-LH for $72 \mathrm{~h}$. Proteins secreted into the medium were analyzed by gelatin zymography 
B

A

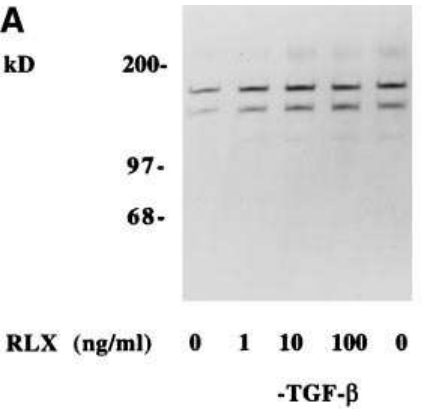

C

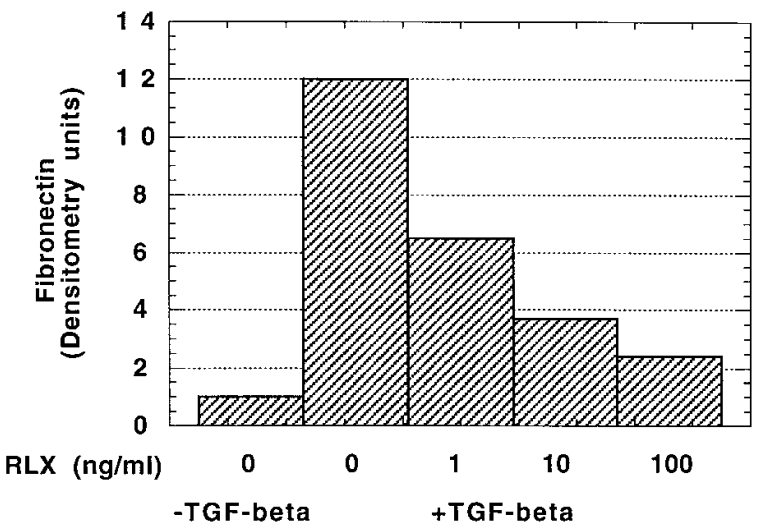

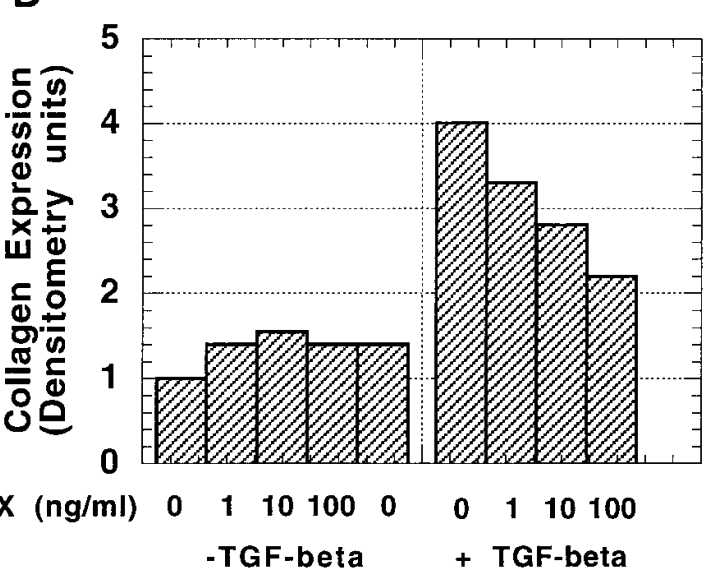

Figure 1. Relaxin inhibition of TGF- $\beta$-induced upregulation of collagen and fibronectin. $(A)$ Human lung fibroblasts (ATCC CCL20) were treated for $24 \mathrm{~h}$ with relaxin (1-100 $\mathrm{ng} / \mathrm{ml})$ with or without the simultaneous addition of TGF- $\beta$ ( $1 \mathrm{ng} / \mathrm{ml})$. Proteins secreted during this period were labeled with $\left[{ }^{3} \mathrm{H}\right]$ proline and resolved on a $4-12 \%$ gradient gel under reducing conditions. The procollagen $(B)$ and fibronectin $(C)$ bands in the autoradiogram shown in $A$ were scanned densitometrically and densities relative to controls

graphed to illustrate the alterations in band intensities. $(D)$ The identity of the band at $220 \mathrm{kD}$ secreted by untreated cells, or those treated with TGF- $\beta$ or TGF- $\beta$ and relaxin was confirmed as fibronectin by Western immunoblotting, as described in Methods.

(Fig. 2 A). Relaxin enhanced the expression of the procollagenase doublet in a biphasic, dose-dependent manner, with a 2.5-3.0-fold induction occurring within a broad peak between $1-100 \mathrm{ng} / \mathrm{ml}$ of relaxin (Fig. 2 B). A similar biphasic response curve was observed in human dermal fibroblasts (7). The 72$\mathrm{kD}$ type IV collagenase (matrix metalloproteinase-2) was also expressed by lung fibroblasts, but its secretion was not altered by the addition of relaxin.

Relaxin inhibited bleomycin-induced fibrosis in a murine model. Relaxin was tested for its ability to inhibit bleomycininduced pulmonary fibrosis in two separate experiments. In both experiments, bleomycin or saline was injected as a single i.v. bolus of $120 \mathrm{U} / \mathrm{kg}$. Relaxin or vehicle (acetate or citrate) was administered by continuous infusion via an osmotic pump, which was implanted subcutaneously $7 \mathrm{~d}$ after the bleomycin or saline injection. Circulating relaxin levels were measured by ELISA in blood drawn at the termination of the experiments (Table I). In each experiment, relaxin levels approximated 50 $\mathrm{ng} / \mathrm{ml}$ in both saline/relaxin and bleomycin/relaxin treatment groups and were undetectable in mice not receiving human relaxin. Saline/acetate-treated animals gained $\sim 20 \%$ of their initial body weight during the 3-wk study, whereas the bleomycin-treated animals gained no weight over the course of the study. The presence of relaxin did not affect weight gain (data not shown).

Histological sections of lungs treated with saline/acetate harvested at the end of the experiment demonstrated the filigreed appearance of alveoli seen in normal lungs (Fig. $3 a$ ). Lungs from saline/relaxin-treated animals were indistinguishable from those of saline/acetate-treated mice (not shown). Lungs from bleomycin/acetate-treated animals were composed of large areas of thickened alveolar walls, accompanied by focal areas completely lacking in normal alveolar structure (Fig. $3 b$ ). Areas of damage in these mice included marked deposition of mature Trichrome-stained collagen within the interstitium, as seen at higher magnification Fig. $3 c$. Trichrome staining was also observed in peribronchiolar areas and in linear fashion surrounding blood vessels (not shown). After bleomycin/relaxin treatment, the appearance of lungs was normalized (Fig. $3 d$ ). In contrast to the Trichrome staining evident in the interstitium of lungs from the bleomycin/acetate-treated mice, staining was only observed in areas surrounding the blood vessels and bronchioles, consistent with the presence of large amounts of normal connective tissue supporting these structures. As seen in Fig. $3 e$, which was photographed at the same magnification as Fig. $3 c$, no Trichrome staining was obvi- 


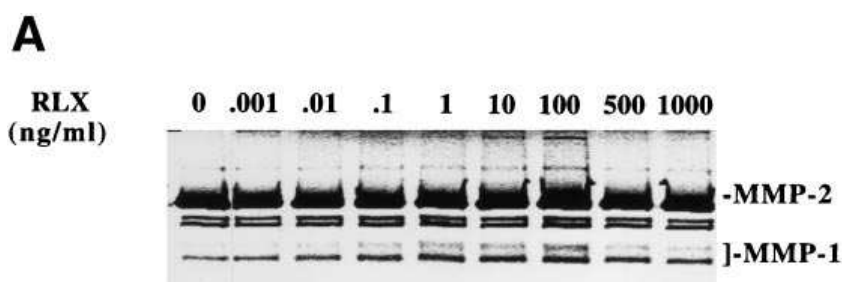

B

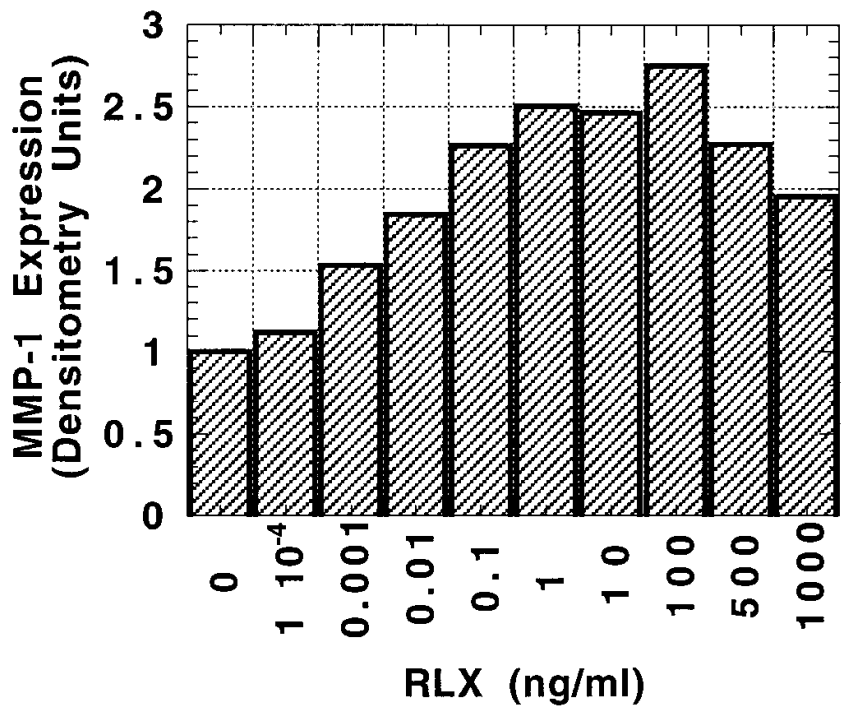

Figure 2. Induction of procollagenase by relaxin. $(A)$ Conditioned media from lung fibroblasts treated with relaxin $(.001-1000 \mathrm{ng} / \mathrm{ml})$ for $72 \mathrm{~h}$ were resolved on a type I gelatin zymogram for detection of matrix metalloproteinase accumulation. The zymogram is shown as a photographic negative to allow easier visualization of bands. The zymogen forms of matrix metalloproteinases-1 and -2 (MMP-1 and MMP-2) are identified. (B) Densities of the bands representing the glycosylated and unglycosylated forms of MMP-1, identified by the brackets in $A$, were graphed to estimate the degree of procollagenase induction by relaxin and its biphasic dose-dependency.

ous in the lung parenchyma of these animals. When H\&E sections of lungs were scored for lung damage in blinded fashion, there was a significant increase in alveolar thickness and fibrosis in lungs from bleomycin-treated animals $(P<0.05)$. This increase was inhibited $64 \%$ by relaxin treatment $(P<0.05)$ (Fig. 4).

The deposition of collagen in the lungs was quantified biochemically in the second experiment as hydroxyproline content (Fig. 5). Treatment of mice with a single intravenous bolus of bleomycin increased the content of hydroxyproline by $28 \%$ over that measured in lungs from mice injected with saline when measured 3 weeks later $(P<0.05)$, comparable to previous reports (8). Administering relaxin for 2 wk by continuous infusion starting $7 \mathrm{~d}$ after bleomycin treatment resulted in a decrease in hydroxyproline content to control levels $(P<$ $0.05)$. Relaxin given to mice in the absence of bleomycininduced fibrosis did not alter pulmonary collagen content (Fig. 5) or morphology (data not shown).

\section{Discussion}

Lung fibrosis is the common outcome of a number of pulmonary diseases, and current therapies are ineffective. In the
Table I. Steady-State Circulating Levels of Human Relaxin in Murine Model

\begin{tabular}{clc}
\hline Experiment & Group & $\begin{array}{c}\text { Steady-state } \\
(\mathrm{RLX}, \mathrm{ng} / \mathrm{ml})^{*}\end{array}$ \\
\hline 1 & Sal/RLX & $45.06 \pm 7.17(8)^{\ddagger}$ \\
& Bleo/RLX & $60.20 \pm 10.41(6)$ \\
2 & Sal/RLX & $44.65 \pm 6.07(14)$ \\
& Bleo/RLX & $54.87 \pm 4.78(16)$ \\
\end{tabular}

Relaxin was delivered by subcutaneously implanted osmotic pumps for 2 wks. At termination of the experiment, circulating concentrations of human relaxin were determined by ELISA. Relaxin was undetectable in mice not receiving human relaxin. *Means \pm SEM. ${ }^{\ddagger}$ Number of animals per group in parentheses.

present study, we evaluated a cytokine, relaxin, for its ability to inhibit connective tissue deposition by lung fibroblasts in vitro and to block lung fibrosis in a murine model. Relaxin's ability to decrease expression of interstitial collagen types I and III by human lung fibroblasts in vitro is consistent with findings on normal human dermal fibroblasts (5) and scleroderma fibroblasts (13). As previously noted and re-emphasized in this study, relaxin is a potent inhibitor of collagen expression when collagen is over-expressed; relaxin does not markedly alter basal levels of collagen expression, in contrast to other collagen-modulatory cytokines, such as interferon- $\gamma$ (14). TGF- $\beta$ was selected as the cytokine stimulator of collagen and fibronectin expression in vitro in this study because a number of reports have implicated it as one of the important inducing agents of lung fibrosis, both in animal models (15) and in human disease (16). Relaxin also decreased fibronectin over-expression in human lung fibroblasts in a dose-dependent manner, indicating that relaxin has the ability to normalize the expression of two connective tissue components that are major contributors to interstitial lung fibrosis.

In vitro, relaxin also modulates the secretion of the matrix metalloproteinase, procollagenase, whose expression is an important regulatory step in the degradation of collagen. The observed relaxin-induced bimodal increase in procollagenase secretion is also consistent with previous findings in human dermal fibroblasts (5) and with data presented in a recent publication on the induction of collagenase in guinea pig cervical cells (17). This increase in procollagenase expression, in conjunction with the down-regulation in collagen and fibronectin secretion, indicates that relaxin induces an extracellular matrix-remodelling phenotype in lung fibroblasts in vitro.

Relaxin's ability to inhibit fibrosis in vivo was tested in a bleomycin-induced lung fibrosis model, which has been used extensively to study the pathogenesis of pulmonary fibrosis (8, 10, 15, 18-23). Previous studies have evaluated the ability of steroidal (20) and nonsteroidal anti-inflammatory drugs (21), and antibodies to chemokines (22) or other inflammatory cytokines (23) to block fibrosis in this model. The present study was designed to evaluate an agent that has a direct effect on collagen and fibronectin deposition, in contrast to previous studies utilizing inhibitors of the inflammatory phase of the bleomycin response. Relaxin treatment was initiated 7 days after bleomycin administration in order to separate the initial inflammatory phase of the response to bleomycin from the re- 

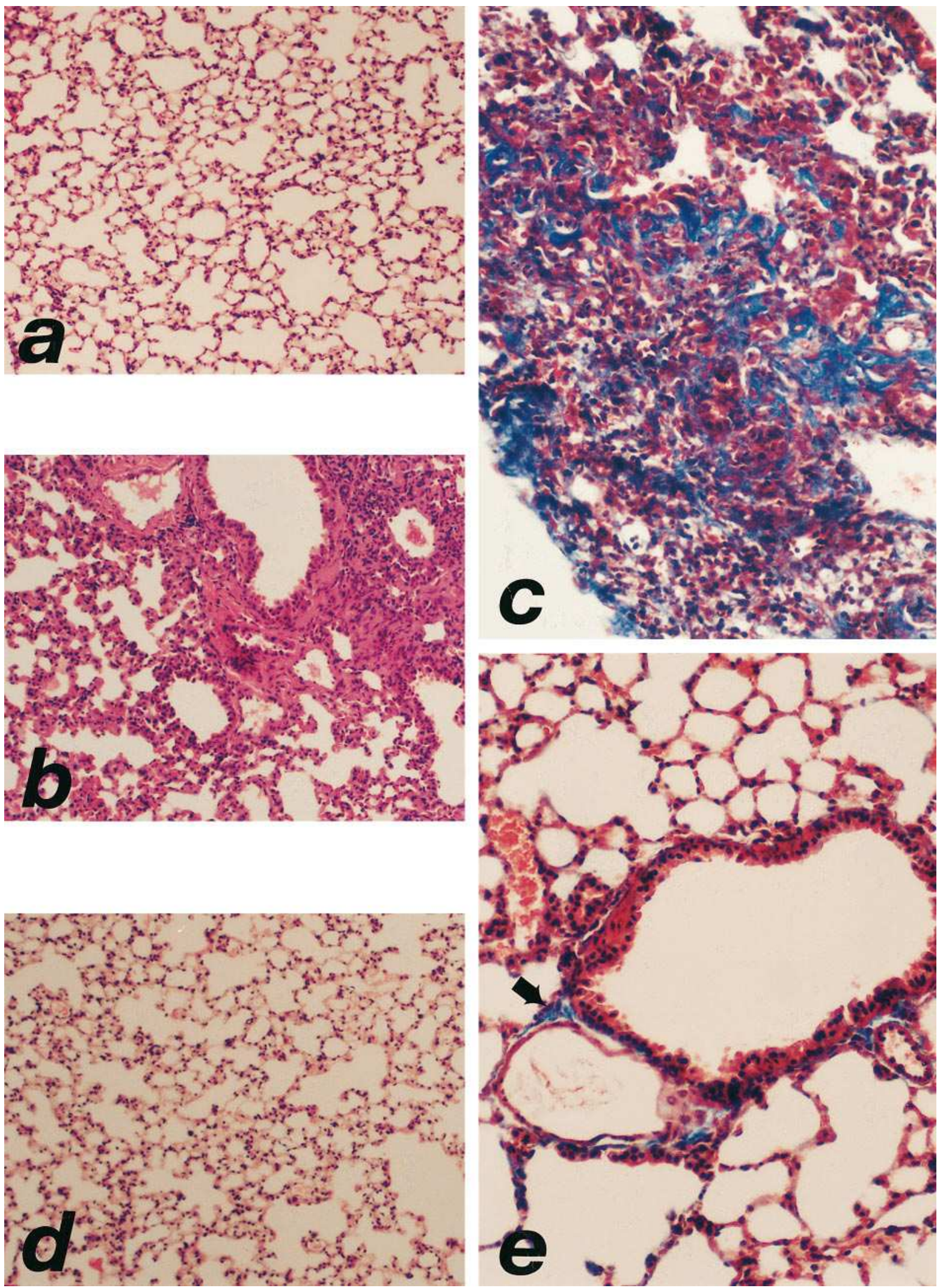

Figure 3. Representative photomicrographs of lungs demonstrating histological changes in response to administration of bleomycin and relaxin. (a) H \& E-stained section of saline/acetate-treated lung demonstrated fine filigreed normal alveolar structure $(\times 1000)$. (b) Lung from bleomycin/acetate-treated animal showed focal loss of alveolar structure, concomitant with increased cellularity and enhanced deposition of extracellular matrix $(\times 1000)$. (c) Trichrome staining of section of lung from bleomycin/acetate-treated animal showed intense blue staining of the interstitium $(\times 2000)$. (d) Lung after bleomycin/relaxin treatment demonstrated normal alveolar morphology. $(\times 1000)$. $(e)$ Trichrome-stained section of lung from bleomycin/relaxin-treated animal was devoid of parenchymal Trichrome staining, but peribronchiolar areas and areas adjacent to blood vessels were stained for collagen $($ arrow $)(\times 2000)$. 


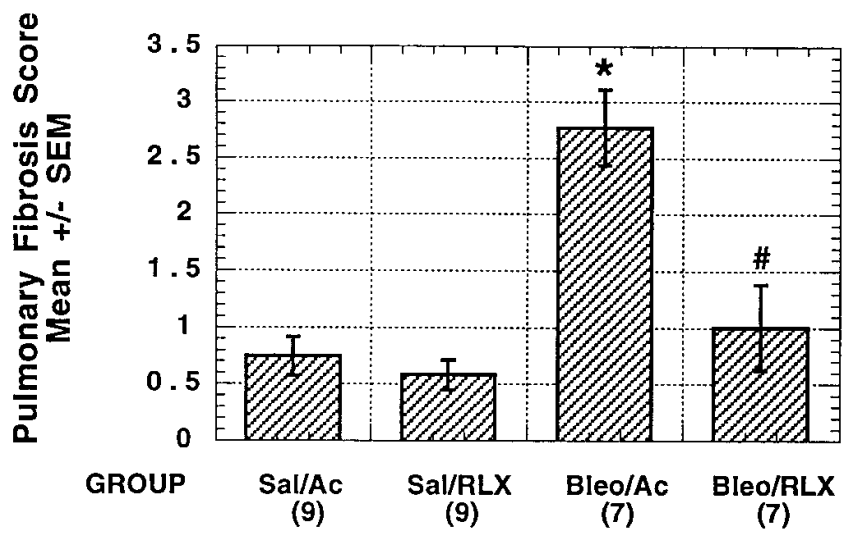

Figure 4. Results of scoring for lung fibrosis demonstrating inhibition of lung damage by relaxin in the bleomycin model. Histological sections of lungs from animals treated with saline/acetate (Sal/Ac), saline/relaxin $(\mathrm{Sal} / R L X)$, bleomycin/acetate (Bleo/Ac), and bleomycin/ relaxin $(B l e o / R L X)$ were stained with $\mathrm{H} \& \mathrm{E}$ and scored in blinded fashion for alveolar thickness. Ten random fields at three levels per lung were scored for thickness and interstitial fibrosis, according to the Ashcroft method (9). Scores ranged from 1-6, with increasing numbers indicating increasing severity of alveolar abnormality. Numbers of animals per treatment group is indicated in parentheses. $* P<$ 0.05 compared with saline/acetate group; ${ }^{\#} P<0.05$ compared with bleomycin/acetate group.

sultant fibrotic process. We have no evidence to suggest that there would be a relaxin effect on the inflammatory component of the response; however, as the focus of the study was inhibition of fibrosis, a time point approximating the start of the repair phase of the response was selected (19). Human relaxin has a two hour half-life after bolus intravenous or subcutaneous administration ( L.B. Pickford and M.E. Erikson, unpublished observations). Therefore, relaxin was continuously in-

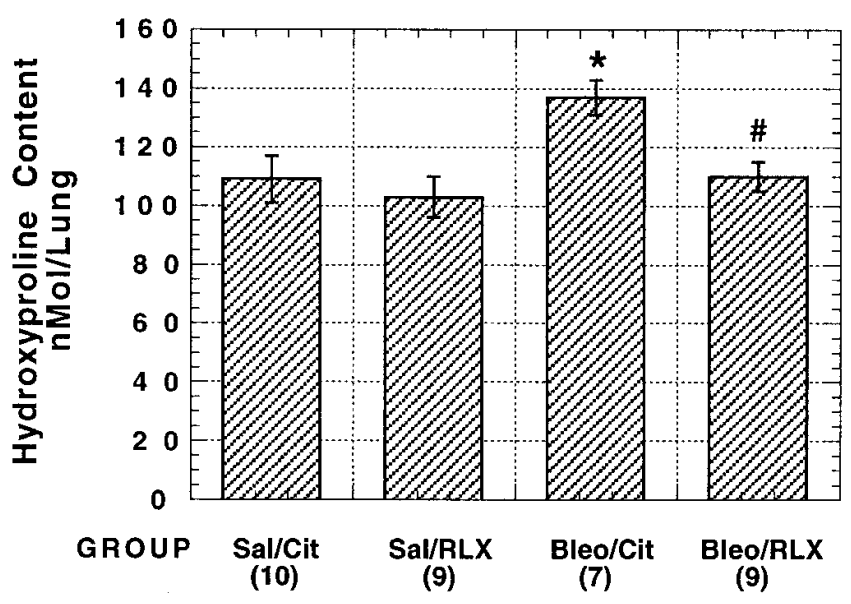

Figure 5. Inhibition of bleomycin-induced collagen accumulation by relaxin in the murine model. Collagen content of the lungs from animals treated with saline/citrate (Sal/Cit), saline/relaxin (Sal/RLX), bleomycin/citrate $(B l e o / C i t)$, and bleomycin/relaxin $(B l e o / R L X)$ was quantified by hydroxyproline measurement and represented as mean nMoles \pm SE on a per lung basis. The number of animals included per treatment group is provided in parentheses. $* P<0.05$ compared with saline/acetate group. ${ }^{\#} P<0.05$ compared with bleomycin/relaxin group. fused from pumps to achieve a steady-state circulating serum level. The intravenous route of bleomycin administration was selected over intratracheal infusion to achieve a more homogenous pattern of fibrosis (L.B. Pickford and E.N. Unemori, unpublished observations) (8). Collagen quantitation by hydroxyproline content, which is not without attendant limitations (24, 25), and histological assessment of lung structure were both used to ascertain degree of fibrosis.

At the end of the study, alveolar thickness was scored in blinded fashion, and showed a statistically significant increase after bleomycin treatment. This enhanced thickness and the development of interstitial fibrosis, as well as the increase in collagen content, were ameliorated by relaxin administration, allowing preservation of normal lung architecture, and presumably, function. Relaxin exposure in the absence of a bleomycin insult did not alter either normal lung histology or the collagen content of this tissue. This is consistent with findings in vitro which demonstrated that collagen and fibronectin were not modulated by relaxin unless they were overexpressed. Although we have shown in vitro that relaxin stimulates procollagenase expression, the role of procollagenase activity in the lung is a matter of speculation; it is possible that some collagen degradation, as well as inhibition of synthesis, contributes to the inhibition of fibrosis.

Previously, we and others have shown in animal models that relaxin can alter the three-dimensional structure of collagen fibers within remodelling tissue $(6,26)$. In our model, capsules formed around subcutaneously implanted relaxinfilled osmotic pumps were comprised of collagen fibrils that were less densely packed and frequently not in ordered parallel arrays to the same extent as they appeared in capsules formed around vehicle-loaded pumps. It has also been shown, in a porcine model of skin expansion, that relaxin can effect tissue expansion without altering dermal thickness (27). Although the cellular mechanisms underlying stress-induced tissue expansion are unclear, the described effect suggests that relaxin can modify the dermal collagenous framework in this model, as well. Steinetz and O'Byrne (28) have speculated that relaxin alters the extent of collagen cross-linking, allowing fibrils to slide past one another and reorient. These studies suggest that, in addition to modulating the quantity of collagen content, relaxin may also mediate changes in the disposition of the collagen that is present. We are currently evaluating methods by which this can be measured in the lung.

The mechanisms behind the inhibition of collagen and fibronectin expression and the upregulation of procollagenase secretion are unknown at the present time. Relaxin binding to its cognate receptor(s) and postreceptor signalling are likely to be complex and cell- and tissue-specific. Relaxin has been reported to enhance cAMP formation in human endometrial (29) and anterior pituitary cells (30), to inhibit $\mathrm{Ca}^{2+}$ influx in myometrial cells (31) and mast cells (32), and to induce protein kinase $\mathrm{C}$ translocation from cytosol to membranes in endometrial cells (33). Additionally, binding of relaxin to certain cell types is estrogen-dependent while binding to others is not (34), and certain phenotypic alterations are dependent on the presence of both relaxin and estrogen while others are not (17). Cells derived from reproductive tissues, such as the cervix and uterus, tend to depend on estrogen pre-exposure in vivo, while binding to (34) and phenotypic effects on cells from nonreproductive tissues, such as skin or lungs (Unemori, unpublished observations), tend to be estrogen-independent. 
In summary, we have found that relaxin can induce an extracellular matrix-degrading phenotype in human lung fibroblasts in vitro and can inhibit lung fibrosis in a murine bleomycin model. Thus, relaxin may provide a means to regulate excess collagen deposition in lung diseases characterized by fibrosis.

\section{Acknowledgments}

We thank Dr. Denny Liggitt, DVM, Ph.D. (University of Washington), for evaluating the histology slides in blinded fashion and with expediency. We are also grateful to Karen Delavan-Boorsma for excellent technical assistance.

\section{References}

1. Sheppard, M.N., and N.K. Harrison. 1992. Lung injury, inflammatory mediators, and fibroblast activation in fibrosing alveolitis. Thorax. 4:1064-1074.

2. McGowan, S.E. 1992. Extracellular matrix and the regulation of lung development and repair. FASEB J. 6:2895-2904.

3. Bell, R.J., L.W. Eddie, A.R. Lester, E.C. Wood, P.D. Johnston, and H.D. Niall. 1987. Relaxin in human pregnancy serum measured with a homologous radioimmunoassay. Obstet. Gynecol. 69:585-589.

4. Chihal, H.J., and L.L. Epsey. 1973. Utilization of the relaxed symphysis pubic of the guinea pig for clues to the mechanism of ovulation. Endocrinology. 93:1441.

5. Unemori, E.N., and E.P. Amento. 1990. Relaxin modulates synthesis and secretion of procollagenase and collagen by human dermal fibroblasts. J. Biol. Chem. 265:10681-10685.

6. Unemori, E.N., L.S. Beck, W.P. Lee, Y. Xu, M. Siegel, G. Keller, H.D. Liggitt, E.A. Bauer, and E.P. Amento. 1993. Human relaxin decreases collagen accumulation in vivo in two rodent models of fibrosis. J. Invest. Dermatol. 101: $280-285$

7. Unemori, E.N., and Z. Werb. 1988. Collagenase expression and endogenous activation in rabbit synovial fibroblasts stimulated by the calcium ionophore A23187. J. Biol. Chem. 263:16252-16259.

8. Lindenschmidt, R.C., A.F. Tryka, G.A. Godfrey, E.L. Frome, and H. Witschi. 1986. Intratracheal versus intravenous administration of bleomycin in mice: acute effects. Toxicol. Appl. Pharmacol. 85:69-77.

9. Ashcroft, T., J.M. Simpson, and V. Timbrell. 1988. Simple method of estimating severity of pulmonary fibrosis on a numerical scale. J. Clin. Pathol. 41: $467-470$.

10. Hesterberg, T.W., J.E. Gerriets, K.M. Resider, A.C. Jackson, C.E. Cross, and J.A. Last. 1981. Bleomycin-induced pulmonary fibrosis: correlation of biochemical, physiological, and histological changes. Toxicol. Appl. Pharmacol. 60:360-370.

11. Glantz, S.A. 1992. The special case of two groups. In Primer of Biostatistics J.D. Jeffers and M.R. Englis, editors. McGraw-Hill, Inc., New York.

12. Sporn, M.B., and A.B. Roberts. 1990. TGF- $\beta$ : problems and prospects. Cell Regul. 1:875-882.

13. Unemori, E.N., E.A. Bauer, and E.P. Amento. 1992. Relaxin alone and in conjunction with interferon- $\gamma$ decreases collagen synthesis by cultured human scleroderma fibroblasts. J. Invest. Dermatol. 99:337-342.

14. Amento, E.P., A.K. Bhan, K.G. McCullagh, and S.M. Krane. 1985. Influences of gamma interferon on synovial fibroblastlike cells. Ia induction and inhibition of collagen synthesis. J. Clin. Invest. 76:837-848.

15. Khalil, N., O. Breznay, M. Sporn, and A.H. Greenberg. 1989. Macrophage production of transforming growth factor- $\beta$ and fibroblast collagen synthesis in chronic pulmonary inflammation. J. Exp. Med. 170:727-737.

16. Khalil, N., R.N. O’Connor, H.W. Unruh, P.W. Warren, K.C. Flanders, and A. Kemp. 1991. Increased production and immunohistochemical localization of transforming growth factor in idiopathic pulmonary fibrosis. Am. $J$. Resp. Cell. Mol. Biol. 5:155-162.

17. Mushayandebvu, T.I., and M.R. Rajabi. 1995. Relaxin stimulates interstitial collagenase activity in cultured uterine cervical cells from nonpregnant but not immature guinea pigs; estradiol-17 $\beta$ restores relaxin's effect in immature cervical cells. Biol. Reprod. 53:1020-1037.

18. Eitzman, D.T., R.D. McCoy, X. Aheng, W.P. Fay, T. Shen, D. Ginsberg, and R.H. Simon. 1996. Bleomycin-induced pulmonary fibrosis in transgenic mice that either lack or overexpress the murine plasminogen activator inhibitor-1 gene. J. Clin. Invest. 97:232-237.

19. Adamson, I.Y.R., and D.H. Bowden. 1979. Bleomycin-induced injury and metaplasia of alveolar type 2 cells. Am. J. Pathol. 96:531-544.

20. Phan, S.J., R.S. Thrall, and C. Williams. 1981. Bleomycin-induced pulmonary fibrosis. Effects of steroid on lung collagen metabolism. Am. Rev. Resp. Dis. 124:428-434.

21. Mall, G., P. Zimmermann, I. Siemens, A. Burkhardt, and H.F. Otto 1991. Prevention of bleomycin-induced fibrosing alveolitis with indomethacin: stereological studies on rat lungs. Virchows Arch. A Pathol. Anat. 419:339-347.

22. Smith, R.E., R.M. Strieter, S.H. Phan, N.W. Lukacs, G.B. Huffnagle, C.A. Wilke, M.D. Burdick, P. Lincoln, H. Evanoff, and S.L. Kunkel. 1994. Production and function of murine macrophage inflammatory protein-1 $\alpha$ in bleomycin-induced lung injury. J. Immunol. 153:4704-4712.

23. Piquet, P.F., M.A. Collart, G.E. Grau, Y. Kapanci, and P. Vassalli. 1989. Tumor necrosis factor/cachectin plays a key role in bleomycin-induced pneumopathy and fibrosis. J. Exp. Med. 170:655-663.

24. Witschi, H.P., A.F. Tryka, and R.C. Lindenschmidt. 1985. The many faces of an increase in lung collagen. Fund. Appl. Toxicol. 5:240-250.

25. Fulmer, J.D., R.S. Bienkowski, M.J. Cowan, S.D. Brehl, K.M. Bradley, V.J. Ferrans, W.C. Roberts, and R.G. Crystal. 1980. Collagen concentration and rates of synthesis in idiopathic pulmonary fibrosis. Amer. Rev. Respir. Dis. 122:289-301.

26. Cheah, S.H., K.H. Ng, V.T. Johgalingam, and M. Ragavan. 1995. The effects of oestradiol and relaxin on extensibility and collagen organisation of the pregnant rat cervix. J. Endocrinol. 146:331-337.

27. Kibblewhite, D., W.F. Larrabee, and D. Sutton. 1992. The effect of relaxin on tissue expansion. Arch. Otolaryngol. Head Neck Surg. 118:153-156.

28. Steinetz, B.G., and E.M. O'Byrne. 1983. Speculations on the probable role of relaxin in cervical dilation and parturition in rats. Semin. Reprod. Endocrinol. 1:335-342.

29. Fei, D.T.W., M.C. Gross, J. Lofgren, M. Mora-Worms, and A.B. Chen. 1990. Cyclic AMP response to recombinant human relaxin by cultured human endometrial cells: a specific and high throughput in vitro bioassay. Biochem. Biophys. Res. Comm. 170:214-220.

30. Cronin, M.J., T. Malaska, and C. Bakhit. 1987. Human relaxin increases cyclic AMP levels in cultured anterior pituitary cells. Biochem. Biophys. Res. Comm. 148:1246-1251.

31. Meera, P., A.M. Monga, E. Stefani, L. Toro, and B.M. Sanborn. 1995 Relaxin stimulates myometrial calcium-activated potassium channel activity via protein kinase A. Am. J. Physiol. 269:C312-C317.

32. Masini, E., D. Bani, M. Bigazzi, P.F. Mannaioni, and T. Bani-Sacchi. 1994. Effects of relaxin on mast cells. In vitro and in vivo studies in rats and guinea pigs. J. Clin. Invest. 94:1974-1980.

33. Kalbag, S.S., M.S. Roginsky, Z. Jelveh, and S. Sulimovici. 1991. Phorbol ester, prolactin, and relaxin cause translocation of protein kinase $\mathrm{C}$ from cytosol to membranes in human endometrial cells. Biochim. Biophys. Acta. 1094: $85-91$.

34. Osheroff, P.L., M.J. Cronin, and J.A. Lofgren. 1992. Relaxin binding in the rat heart atrium. Proc. Natl. Acad. Sci. USA. 89:2384-2388. 